\title{
Papers
}

\section{Effect of strategies to reduce exposure of infants to environmental tobacco smoke in the home: cross sectional survey}

\author{
Clare Blackburn, Nick Spencer, Sheila Bonas, Christine Coe, Alan Dolan, Rob Moy
}

\begin{abstract}
Objective To examine parents' reported knowledge and use of harm reduction strategies to protect their infants from exposure to tobacco smoke in the home, and the relation between reported use of strategies and urinary cotinine to creatinine ratios in the infants. Design Cross sectional survey.

Settings Coventry and Birmingham.

Main outcome measures Parents' reported knowledge and use of harm reduction strategies and urinary cotinine to creatinine ratios in their infants. Participants 314 smoking households with infants. Results $86 \%$ of parents (264/307) believed that environmental tobacco smoke is harmful, $90 \%$ (281/314) believed that infants can be protected from it in the home, and 10\% (32/314) were either unaware of measures or reported using none. $65 \%$ of parents (205/314) reported using two or more measures, but only $18 \%(58 / 314)$ reported not allowing smoking in the home. No difference was found in mean log e transformed urinary cotinine to creatinine ratio in infants from households that used no measures compared with households that used less strict measures. Mean log cotinine to creatinine ratios were significantly different in households banning smoking in the home compared with those using less strict or no measures. Banning smoking in the home was independently associated with a significant reduction in urinary cotinine to creatinine ratio by a factor of 2.6 (1.6 to 4.2) after adjustment for average household cigarette consumption, tenure, and overcrowding. Conclusions Less than a fifth of parents in smoking households ban smoking in the home. Banning smoking was associated with a small but significant reduction in urinary cotinine to creatinine ratio in infants, whereas less strict measures compared with no measures had no effect on the infants' exposure to environmental tobacco smoke.
\end{abstract}

\section{Introduction}

Exposure of infants to environmental tobacco smoke is associated with an increased risk of sudden infant death syndrome, asthma, and other respiratory conditions. ${ }^{1}$ In England, children's exposure to tobacco smoke has decreased since the late 1980 s, but there is little evidence of reduced consumption of tobacco by parents in the presence of their children. ${ }^{2}$ Smoking cessation among household members is the only effective way of reducing passive smoking among young people. Changing smoking practices in the home and in the presence of young people has been suggested as a means of reducing exposure to tobacco smoke when cessation is not possible. To date the evidence on the use and effectiveness of such measures is limited and confusing.

Most studies examining harm reduction strategies by parents in the home report on children with specific conditions such as asthma, where parents' knowledge and use of measures to reduce exposure to tobacco smoke is likely to be higher than in the general population. ${ }^{3-5}$ Neither of the studies on community samples of infants reported the range of measures parents know about and adopt to protect their infants. ${ }^{67}$

Data on the effectiveness of harm reduction measures in households with infants are also limited. Three studies examined harm reduction interventions in households with infants. ${ }^{8-10}$ Little effect was found of the strategies as measured by the infants' urinary cotinine to creatinine ratios, although none of the studies reported the effect size for not smoking in the home. Other studies were carried out among older children or an age range including older children and infants, ${ }^{6}{ }^{11-18}$ and three did not measure cotinine as an outcome. ${ }^{612}{ }^{16}$ Published observational studies have studied older children and adolescence (1-19 years) in hospital outpatient populations. ${ }^{3}{ }^{19} 20$ These reported decreased cotinine concentrations associated with harm reduction strategies; however, whereas two reported decreased cotinine concentrations associated with strategies short of a total ban on smoking in the home, ${ }^{3}{ }^{19}$ one showed a reduction associated with a smoking ban but not with less strict measures, although no adjustment was made for potential confounders. ${ }^{20}$

We report parents' knowledge and use of measures to reduce exposure of their infants to environmental tobacco smoke and the impact of harm reduction measures on urinary cotinine to creatinine ratios in infants. Our sample was community based and representative of UK smoking households with infants (mean age 12.8 weeks).
School of Health and Social Studies, University of Warwick, Coventry CV4 7AL Clare Blackburn senior lecturer Nick Spencer professor of child health

Christine Coe research fellow Alan Dolan lecturer

Department of Epidemiology and Public Health,

University of

Leicester, Leicester

LE1 6TP

Sheila Bonas

lecturer in health

psychology

Institute of Child

Health,

Birmingham

Children's Hospital,

Birmingham

Rob Moy

senior lecturer in

community

paediatrics

Correspondence to:

C Blackburn

c.m.blackburn@

warwick.ac.uk

bmj.com 2003;327:257 


\section{Participants and methods}

We used a cross sectional survey design to collect data from a sample of parents of infants living in households with one or more smokers. The parents of infants born to mothers living within the boundaries of two community NHS trusts in the West Midlands over a nine month period were asked to participate in the study by their family health visitors. Infants with major perinatal illnesses were excluded. Sample size estimation was based on power sufficient to detect a $30 \%$ reduction in the infants' mean urinary cotinine to creatinine ratios associated with strict harm reduction measures significant at the $5 \%$ level and with a power of $80 \%$.

Parents (98\% of whom were mothers) were interviewed at home by a trained nurse using a structured schedule. Participants whose first language was not English were offered an interpreter. Interviews took place when infants were between 4 and 24 weeks old.

Data were collected on knowledge and use of harm reduction strategies, tobacco consumption of household members, personal details, and characteristics of the home environment. A sample of the infant's urine was collected, by a pad inserted into the nappy, for estimation of the urinary cotinine to creatinine ratio. Urinary cotinine $(\mathrm{ng} / \mathrm{ml})$ was measured by ELIZA, a competitive enzyme immunoassy method, which has been shown to have the specificity and sensitivity to detect cotinine at low levels. The ratio of cotinine to creatinine $(\mathrm{mmol} / \mathrm{l})$ was measured to adjust for dilution of the urine.

Smoking households were defined as households with one or more resident tobacco smokers (cigarettes, pipes, or cigars). We analysed the data using frequencies and bivariate analyses to describe and assess differences in knowledge and use of harm reduction measures between households. To examine differences between groups in the frequency distribution of categorical variables, we used the Pearson $\chi^{2}$ test, unless the expected cell size was less than five, when we used Fisher's exact test.

To examine the relation between use of harm reduction strategies and infant urinary cotinine to creatinine ratios, we dichotomised the strategies as strict (smoking banned in the home) versus less strict (smoking permitted in the home but restrictions placed on smoking in the vicinity of the baby or active steps taken to air room after smoking) or none used or main carers not aware of strategies. As the urinary cotinine to creatinine ratios were not normally distributed (skewness 6.66; kurtosis 53.55), we performed logarithmic e transformation and recorded the results as geometric means. Of the 164 households with bottle fed infants for whom full data were available, $31(19 \%)$ used strict measures, $111(68 \%)$ less strict measures, and $22(13 \%)$ used no measures or were not aware of any. Mean log urinary cotinine to creatinine ratios were not significantly different in the less strict and none or not aware groups (2.61, 2.41 to $2.81 v 2.43,1.83$ to 3.03$)$, so the harm reduction variable was dichotomised to strict versus less strict, none, or not aware. To adjust for potential confounding by respondent's and partner's average daily cigarette consumption (continuous variables), housing tenure (rented versus owner occupied), and overcrowding (more than one person per room versus one or fewer people per room), linear regression models including these variables were fitted on log urinary cotinine to creatinine ratios. Only bottle fed infants were included in this analysis, as nicotine and cotinine are transmitted to infants through breast milk. ${ }^{21}$ All analyses were undertaken in SPSS version 10.0.

\section{Results}

Overall, 314 smoking households with young infants took part in our study (table 1). Compared to all UK households with infants, the study households were more likely to be from a lower social class and mothers were more likely to have left school aged 16 years or less, reflecting the association between tobacco use and social disadvantage. The 236 parents who declined to take part were more likely to be younger and from a black or ethnic minority group than those who participated. The proportions of participants who were black or from a ethnic minority group were, however, similar to those in the communities from which they were recruited.

A high proportion of parents believed that children's health is affected a great deal or quite a lot by people smoking in the home and that it is possible to protect children from exposure to tobacco smoke (table 2). Only one in 10 parents was unaware of any

Table 1 Personal characteristics of smoking households with infants. Values are numbers (percentages) of households unless stated otherwise

Characteristics

Households $(n=314)$ Parent's age (years):

\begin{tabular}{|c|c|}
\hline$\leq 24$ & $100(32)$ \\
\hline$\geq 25$ & $214(68)$ \\
\hline \multicolumn{2}{|l|}{ Status: } \\
\hline Living with partner & $267(85)$ \\
\hline Not living with partner & $47(15)$ \\
\hline \multicolumn{2}{|l|}{ No of children: } \\
\hline $1-3$ & $267(85)$ \\
\hline$\geq 4$ & $47(15)$ \\
\hline \multicolumn{2}{|l|}{ Self reported ethnic group: } \\
\hline White (United Kingdom or European) & $256(82)$ \\
\hline Other & $58(18)$ \\
\hline \multicolumn{2}{|l|}{ Tenure: } \\
\hline Owner occupied & $148(47)$ \\
\hline Rented or other & $166(53)$ \\
\hline \multicolumn{2}{|l|}{ Parent's educational achievement: } \\
\hline No qualifications & $72(23)$ \\
\hline Qualifications & $242(77)$ \\
\hline \multicolumn{2}{|l|}{ No of rooms per person: } \\
\hline$\leq 1$ & $103(33)$ \\
\hline$>1$ & $204(65)$ \\
\hline Missing data & $7(2)$ \\
\hline \multicolumn{2}{|l|}{ Social class of household: } \\
\hline Non-manual & $70(22)$ \\
\hline Manual & $131(42)$ \\
\hline Part time worker & $14(4.5)$ \\
\hline Unemployed & $97(31)$ \\
\hline Missing data & $2(0.5)$ \\
\hline \multicolumn{2}{|l|}{ Total household income per annum: } \\
\hline$<£ 10000$ & $148(47)$ \\
\hline$\geq £ 10000$ & $166(53)$ \\
\hline Mean age of infants studied & 12 weeks \\
\hline $\begin{array}{l}\text { Mean (SD) cotinine to creatinine ratio } \\
(\mathrm{ng} / \mathrm{ml}: \mathrm{mmol} / \mathrm{l}) \text {; range }(\mathrm{n}=216)\end{array}$ & $30.3(73.0) ; 1-726$ \\
\hline
\end{tabular}


Table 2 Beliefs and knowledge of parents from 314 smoking households about exposure of their infants to environmental tobacco smoke

\begin{tabular}{ll}
\hline Beliefs and knowledge & $\%$ (No) \\
\hline Exposure to tobacco smoke affects children's health: & $50(155)$ \\
\hline A great deal & $35(109)$ \\
\hline Quite a lot & $14(43)$ \\
\hline A little or not at all & \\
\hline $\begin{array}{l}\text { Are there practical things people can do to protect children } \\
\text { from environmental tobacco smoke? }\end{array}$ & $89(281)$ \\
\hline Yes & $10(32)$ \\
\hline No or do not know of any & $90(282)$ \\
\hline Able to recall one or more measures to protect infants from \\
\hline environmental tobacco smoke & $30(94)$ \\
\hline Measures parents were able to recall ${ }^{*}:$ & $25(80)$ \\
\hline Do not smoke, or allow smoking, in house & $34(106)$ \\
\hline Stop smoking & $11(35)$ \\
\hline Avoid smoky places & $56(175)$ \\
\hline Smoke fewer cigarettes & $18(58)$ \\
\hline Do not smoke in same room as child & $25(80)$ \\
\hline Do not smoke, or allow smoking, in living room & $31(97)$ \\
\hline Do not smoke, or allow smoking, where child sleeps or naps \\
\hline Air room when smoking or someone else is smoking \\
\hline Air room after smoking or after someone else has smoked & $24(75)$ \\
\hline Other† & $24(75)$ \\
\hline
\end{tabular}

${ }^{*}$ Sum of percentages exceeds $100 \%$, as carers reported more than one measure.

†Includes: do not allow smoker to hold baby wearing smoky clothes or soon after smoking; wash hands after smoking; use ioniser or fan; do not smoke over child (assume still in same room); use air freshener.

measures to reduce exposure. More than half the parents reported using more than one measure (table 3). Just under a fifth reported banning smoking in the home.

Complete data were available on 164 bottle fed infants. The following analyses relate to these infants only. The mean log cotinine to creatinine ratio for use of strict harm reduction measures was 1.26 (0.68 to 1.82 ) and was significantly lower than that for less strict or no measures $(2.58,2.38$ to 2.78$)$. In linear regression models fitted on the log cotinine to creatinine ratio, strict harm reduction was associated with a significant reduction in the ratio independent of respondent's and partner's average daily cigarette consumption, tenure, and overcrowding (table 4). The final model including all these exposure variables accounted for $31 \%$ of the variance in urinary cotinine to creatinine ratio. Expressed as an arithmetic mean, use of strict harm reduction measures is associated with a reduction in urinary cotinine to creatinine ratio of 2.6 (1.6 to 4.2 ).

\section{Discussion}

Banning smoking in the home is associated with a small but significant reduction in urinary cotinine to creatinine ratios in infants, whereas less strict measures compared with no measures to reduce tobacco smoke in the home had no effect on exposure of infants. Our study is the first to report, in detail, parents' knowledge and use of measures to reduce the exposure of their infants to tobacco smoke in the home. Our sample was more socially disadvantaged than all UK households with infants, consistent with the known association between smoking and social disadvantage. ${ }^{22}$

Only a small proportion of respondents reported not knowing of any harm reduction measures or knowing of measures but not using them. This suggests that health promotion messages urging parents to protect their children from tobacco smoke may have had some success. However, we found that parents would benefit from more information on what measures actually work. Many of the harm reduction strategies used by the parents, such as opening windows when smoking and using fans and ionisers, were ineffective. The parents frequently used a combination of measures, making it difficult to determine the extent to which individual practices affect exposure.

Our finding that banning smoking in the home is associated with a significant reduction in infant urinary cotinine, after adjustment for household cigarette consumption, is consistent with three studies of older children. ${ }^{3}{ }^{19}{ }^{20}$ In contrast to our findings, however, two reported significant reductions in cotinine levels associated with less strict measures. ${ }^{3}{ }^{19}$ The age range of our infants was chosen to coincide with the age of greatest vulnerability to sudden infant death; harm reduction measures that are effective in households with older children may be ineffective in households with young infants because of their lack of independent mobility and speed of metabolism. ${ }^{23}$

\section{Limitations of study}

Our study had some limitations. We measured urinary cotinine on only one occasion, although levels vary if serial measurements are taken. ${ }^{5}$ Individual cotinine levels depend on the number of smokers in the household, the number of cigarettes smoked, proximity to smokers, the extent of crowding in the home, the size of rooms, ventilation, and whether there is exposure to environmental tobacco smoke in vehicles.

Although we have included levels of smoking and overcrowding in the household in our model, we have no data on the size of the rooms or the extent of ventilation. The number of parents that used no harm reduction strategies was small, which may have reduced the precision of the mean urinary cotinine to creatinine ratio for this group making it difficult to

Table 3 Use of measures by parents from 314 households to reduce exposure of their infants to environmental tobacco smoke at home

\begin{tabular}{|c|c|c|}
\hline Details of measures & $\%(\mathrm{No})^{\star}$ & \\
\hline \multicolumn{2}{|l|}{ No of measures used: } & \\
\hline None & $12(38)$ & \\
\hline 1 & $22(70)$ & \\
\hline 2 & $12(38)$ & \\
\hline$\geq 3$ & $53(167)$ & \\
\hline \multicolumn{2}{|l|}{ Measures used: } & \\
\hline Do not smoke, or allow smoking, in house & $18(58)$ & \\
\hline Stopped smoking & $3(9)$ & \\
\hline Smoke fewer cigarettes & $14(43)$ & \\
\hline Do not smoke, or allow smoking, in same room as child & $49(153)$ & \\
\hline Do not smoke, or allow smoking, in living room & $24(74)$ & \\
\hline Do not smoke, or allow smoking, where child sleeps or naps & $34(106)$ & \\
\hline Air room when smoking or someone else smoking & $46(144)$ & \\
\hline Air room after smoking or after someone else has smoked & $43(134)$ & \\
\hline Other* $^{*}$ & $39(124)$ & \\
\hline \multicolumn{2}{|l|}{ Severity of measures used: } & \\
\hline Strict & $18(58)$ & \\
\hline Less strict & $69(218)$ & \\
\hline None or not aware of any & $12(38)$ & \\
\hline
\end{tabular}

Sum of percentages exceeds $100 \%$ as carers reported more than one measure. Includes: not allow smoker to hold baby wearing smoky clothes or soon after smoking; wash hands after smoking; use ioniser or fan; do not smoke over child (assume still in same room); use air freshener. 
Table 4 Linear regression model fitted on log cotinine to creatinine ratios in bottle fed infants from 164 households with complete data

\begin{tabular}{lcccc} 
Independent variables & $\mathbf{B}$ coefficient $\mathbf{( 9 5 \% ~ C l )}$ & t statistic & P value & $\mathbf{R}^{2}$ change $(\%)$ \\
\hline Strict harm reduction measures & $-0.97(-1.44$ to -0.50$)$ & -4.09 & $<0.001$ & $0.146(14.6)$ \\
\hline Parent's average daily cigarette consumption & $0.05(0.03$ to 0.07$)$ & 4.54 & $<0.001$ & $0.261(26.1)$ \\
\hline Housing tenure (rented) & 0.58 & 3.05 & 0.003 & $0.304(30.4)$ \\
\hline Partner's average daily cigarette consumption & $0.003(-0.017$ to 0.001$)$ & 0.42 & 0.677 & $0.305(30.5)$ \\
\hline Overcrowding & $0.004(-0.002$ to 0.01$)$ & 0.58 & 0.562 & $0.306(30.6)$
\end{tabular}

detect a true difference between those using less strict strategies and those using none.

\section{Strengths of study}

The strengths of our study were that we sampled a representative population of smoking households with infants, we assessed the cotinine to creatinine ratio, which corrects for dilution of urine, ${ }^{22}$ and we studied a narrow age range of infants thus reducing the variation associated with differential speed of metabolism and excretion of nicotine. Previous observational studies were based on selected populations (hospital outpatients and children with asthma), parental reporting of cigarette consumption, and wide age ranges. ${ }^{3}{ }^{19} 20$

The group we studied was chosen to coincide with the peak age for sudden infant death syndrome. Reducing the exposure of infants to tobacco smoke is likely to be important in preventing sudden infant death as there is a close association between the two. Our results suggest that, independent of major confounding variables, banning smoking in the home significantly reduces infant exposure to environmental tobacco smoke but, as there are no data directly relating cotinine levels to risk of death, it is not possible to predict the likely effect of a reduction of this magnitude on the risk of sudden infant death. Our results also suggest that harm reduction measures short of a total ban on smoking in the home are likely to have little effect on the exposure of infants to tobacco smoke, but this requires verification with a larger sample.

We thank the parents who participated; the health visitors, their managers, and staff in the child health departments of the NHS

\section{What is already known on this topic}

Reducing exposure to environmental tobacco smoke in early life may reduce the risk of sudden infant death syndrome and improve health outcomes

Smoking cessation is difficult for some parents, especially those who are socially disadvantaged

Randomised controlled trials of strategies to reduce exposure of infants to smoke have shown little effect, but none report the effect of not smoking in the home

\section{What this study adds}

Banning smoking in the home has a small but significant effect on urinary cotinine levels in infants, independent of household cigarette consumption, housing tenure, and overcrowding

Harm reduction measures have little or no effect on urinary cotinine levels in infants trusts who helped us to recruit our sample; and the nurses who collected the data.

Contributors: CB and NS as principal investigators had primary responsibility for the study design, project management, and planning of the analysis. They were assisted by CC and RM. SB and $\mathrm{AD}$ supervised the data collection, data entry, and interviewers. $\mathrm{CB}$, NS, and $\mathrm{SB}$ created the variables and carried out the data analysis. $\mathrm{CB}$ and NS wrote the paper with comments from $\mathrm{SB}, \mathrm{CC}, \mathrm{AD}$, and $\mathrm{RM}$. $\mathrm{CB}$ and NS will act as guarantors for the paper.

Funding: NS, CB, CC, and RM were supported by the Foundation for the Study of Infant Deaths (grant No 266).

Competing interests: None declared.

Ethical approval: This study was approved by the Coventry and south Birmingham research ethics committees.

1 Cook DG, Strachan DP. Health effects of passive smoking: summary of effects of parental smoking on the respiratory health of children and implications for research. Thorax 1999;54:357-66

2 Jarvis M, Goddard E, Higgins V, Feyerabend C, Bryant A. Children's exposure to passive smoking in England since the 1980s: cotinine evidence from population surveys. BMJ 2000;321:343-5.

3 Wakefield M, Banham D, Martin J, Ruffin R, McCaul K, Badcock N. Restrictions on smoking at home and urinary cotinine levels among children with asthma. Am J Prev Med 2000;19:188-92.

4 Emerson J, Wahlgren D, Hovell M, Meltzer S, Zakarian J, Hofstetters C. Parent smoking and asthmatic children's exposure patterns. Addict Behav 1994;19:677-89.

5 Peterson EL, Johnson CC, Ownby DR. Use of urinary cotinine and questionnaires in the evaluation of infant exposure to tobacco smoke in epidemiologic studies. J Clin Epidemiol 1997;8:917-23.

6 Erikson W, Bruusgaard D. Smoking behaviour in young families: do parents take practical measures to prevent passive smoking by the children? Scand J Prim Health Care 1995;13:275-80.

7 Hiley C, Morley C. Risk factors for sudden infant death syndrome: further change in 1992-3. BMJ 1996;312:1397-8.

8 Woodward A, Owen N, Grgurinovitch N, Griffith F, Linke H. Trial of an intervention to reduce passive smoking in infancy. Pediatr Pulmonol 1987:3:173-8.

9 Chilmonczyk B, Palomaki G, Knight G, et al. An unsuccessful cotinine-assisted intervention strategy to reduce environmental tobacco smoke exposure during infancy. AJDC 1992;146:357-60.

10 Greenberg R, Stretcher V, Bauman K, Boat B, et al. Evaluation of a homebased intervention program to reduce infant passive smoking and lower respiratory illness. J Behav Med 1994;17:273-89.

11 Irvine L, Crombie IK, Clark RA, et al. Advising parents of asthmatic children on passive smoking: randomised controlled trial. $B M J$ 1999;318:1456-61.

12 Hovell MF, Meltzer SB, Zakarian JM, et al. Reduction in environmental tobacco smoke exposure among asthmatic children: a controlled trial. Chest 1994;106:440-6.

13 Wilson SR, Yamada EG, Sudhakar R, Roberto L, Mannino D, Mejia C, et al. A controlled trial of an environmental tobacco smoke reduction intervention in low-income children with asthma. Chest 2001;120:1709-22.

14 Wakefield M, Banham D, McCaul K, Martin J, Ruffin R, Badcock N, et al Effect of feedback regarding urinary cotinine and brief tailored advice on home smoking restrictions among low-income parents of children with asthma: a controlled trial. Prev Med 2002:34:58-65.

15 Hovell MF, Zakarian JM, Matt GE, et al. Effect of counselling mothers on their children's exposure to environmental tobacco smoke: randomised controlled trail. BMJ 2000;321:337-42.

6 Emmons KM, Hammond K, Fava JL, et al. A randomised trial to reduce passive smoke exposure in low income households with young children. Pediatrics 2001:108:18-24

17 McIntosh NA, Clark NM, Howatt WF. Reducing tobacco smoke in the environment of the child with asthma A cotinine-assisted minimal contact intervention. J Asthma 1994;431:453-62.

18 Erikson W, Sørum K, Bruusgaard D. Effects of information on smoking behaviour in families with preschool children. Acta Pediatr 1996;85:209 12.

19 Bakoula C, Kafritsa Y, Kavadias G, et al. Factors modifying exposure to environmental tobacco smoke in children. Cancer Causes Control $1997 ; 8: 73-6$.

20 Winklestein M, Tarzian A, Wood R. Parental smoking behaviour and passive smoke exposure in children with asthma. Ann Allergy Asthma Immunol 1997;78:419-23.

21 Mascola MA, Van Vunakis H, Tager IB, et al. Exposure of young infants to environmental tobacco smoke: breast-feeding among smoking mothers. Am J Public Health 1998;88:893-6. 
22 Graham H. When life's a drag: women, smoking and disadvantage. London: (Accepted 9 May 2003) HMSO, 1993.

23 Haufroid V, Lison D. Urinary cotinine as a tobacco-smoke exposure index: a mini review. Int Arch Occup Environ Health 1998;71:162-8. 